INTERNATIONAL JOURNAL OF RESEARCHES IN BIOSCIENCES, AGRICULTURE AND TECHNOLOGY (C) VISHWASHANTI MULTIPURPOSE SOCIETY (Global Peace Multipurpose Society) R. No. MH-659/13(N) www.vmsindia.org

\title{
SUBSTITUTION OF TRANSITION METAL ION ON MAGNETIC BEHAVIOR of CA0.5SR0.5MEXFE12-2XO19 BY SOLID STATE DIFFUSION PROCESS
}

\author{
M. N. Giriya ${ }^{1}$, C. L. Khobaragade ${ }^{2}$, D. S. Bhowmick ${ }^{3}$, \\ K. G. Rewatkar ${ }^{4}$ and R. P. Tandon 5 \\ ${ }^{1}$ Smt. Radhikatai Pandav College of Engineering, Nagpur, \\ 2,Govindrao Wanjari college of Engg. \& Tech, Nagpur, India \\ 3,Julelal college of Engineering, Nagpur, India \\ 4,Dr. Ambedkar College, Nagpur, India \\ 5,University of Delhi, Delhi, India \\ mohan.giriya@rediffmail.com
}

\begin{abstract}
:
Ca-Sr hexaferrite samples with chemical composition Ca0.5Sro.5 $\mathrm{Me}_{\mathrm{x}} \mathrm{Fe}_{12-2 \mathrm{x}} \mathrm{O}_{19}$ where $(\mathrm{x}=0,0.5,1)$ and $(\mathrm{Me}=\mathrm{CoTi})$ synthesized using proper stoichiometric proportions by solid state reaction at $1040^{\circ} \mathrm{C}$ for $105 \mathrm{hr}$. The chemical phase analysis has been carried out by X-ray powder diffraction (XRD) method, which confirms the formation of the ferrite structure. It shows hexagonal magnetoplumbite (M) type structure having unit cell dimension ' $a$ ' and 'c' varies between 5-6 $\AA$ and 21-23 $\AA$. Coercivity (Hc), saturation magnetization (Ms), Retentivity (Mr) and Bohr magnetron $\left(\eta_{B}\right)$ measurements were carried out on a vibrating sample magnetometer (VSM) with an applied field up to $10 \mathrm{KOe}$. The results were explained in the light of Gorter's (1957) spin model. The magnetiza-tion results indicate that the $\mathrm{Al}^{+3}$ ions preferentially occupy the $2 \mathrm{a}, 12 \mathrm{k}$, and $4 \mathrm{f} 2$ sites. This confirms the use of samples in the various applications of digital data storage devices.

Keywords: X-ray density, porosity, magnetization, coercivity, retentivity etc.
\end{abstract}

\section{Introduction:}

$\mathrm{Ca} / \mathrm{Sr}$ Ferrite, iso-structural with magnetoplumbite ferrites are widely used in permanent magnet market because of their low price combined with reasonable magnetic performances and wide availability of raw materials. Permanent magnets are characterized by high remanance, coericivity etc. [1]. Another advantage is the great chemical stability of these oxides, which makes in such a context a little improvement of their magnetic properties of great importance. Ferrite are technologically important materials because of their interesting physical and chemical properties that have attractive microwave device application i.e. micro strip antennas, radio frequency coil, high density recording media, computer memory chip, transformer coil, etc.[2-4].

The magnetic properties of hexagonal ferrites depend on the intrinsic magnetic properties of the M-type phase. The M-type ferrite crystallizes in a hexagonal structure with 64 ions per unit cell on 11 different symmetry sites. The $24 \mathrm{Fe}^{+3}$ atoms are distributed over five distinct sites: three octahedral sites $(12 \mathrm{k}, 2 \mathrm{a}$ and $\left.4 f_{2}\right)$, one tetrahedral $\left(4 f_{1}\right)$ site and one bipyramidal site $(2 \mathrm{~b})$. The magnetic structure given by the Gorter model in the ferrimagnetic with five different sub-lattices, three parallel $(12 \mathrm{k}, 2 \mathrm{a}$ and $2 \mathrm{~b})$ and two anti-parallel $\left(4 \mathrm{f}_{1}\right.$ and $4 f_{2}$ ) which are coupled by super-exchange interactions through the $\mathrm{O}^{-2}$ ions [5-6].

To understand the lattice behavior of Mtype ferrite, in the present work, a significant improvement of the intrinsic magnetic properties of compounds can be obtained by the partial substitution of CoAl and CoTi. It has recently been shown that La-Co substitute $\mathrm{SrFe}_{12} \mathrm{O}_{19}$ ferrite have improved magnetic properties [2, 4, 7-8]. This improvement is largely associated with the increase of coercivity and underlying magneto-crystalline anisotropy. On the other hand, the complete substitution of Sr by La induces an increase of the anisotropy field [2]. In this way, a rare earth ion may contribute to a change of new magnetic interactions, thus improving the magnetic properties.

In this paper, we have investigated the structural analysis of M-type calcium hexaferrite with composition of $\mathrm{Sr}$ or (CoAl / CoTi) in Ca0.5 $\mathrm{Sr}_{0.5} \mathrm{Me}_{\mathrm{x}} \mathrm{Fe}_{12-2 \mathrm{x}} \mathrm{O}_{19}$ prepared and observed the variation in the magnetic properties.

\section{Experimental:}

The powdered samples of Ca0.5 $\mathrm{Sr}_{0.5} \mathrm{Me}_{\mathrm{x}} \mathrm{Fe}_{12-2 \mathrm{x}} \mathrm{O}_{19}$ have been synthesized by using standard solid state reaction technique. The stoichiometric proportions of weighted oxides were mixed thoroughly in acetone medium for $5 \mathrm{~h}$ and pre-sintered at $500{ }^{\circ} \mathrm{C}$ for $10 \mathrm{~h}$ to homogenize \& calcinations. The calcinated powder were pressed into pellet and sintered at $1040{ }^{\circ} \mathrm{C}$ in air atmosphere for about $96 \mathrm{~h}$ and slowly cooled to room temperature at the rate of $2{ }^{\circ} \mathrm{C} / \mathrm{min}$ using a microprocessor controlled furnace.

The X-Ray diffractograms were obtained using $\mathrm{Cu}-\mathrm{Ka}$ radiation on a Philips X-ray diffractometer (model PW1732). The XRD pattern shows a single crystalline phase without 
traces of impurities. The pattern were indexed to hexagonal magnetoplumbite structure pertaining to the space group $\mathrm{P}_{3} / \mathrm{mmc}$ (No.194). The X-ray powder diffraction pattern of $\mathrm{Ca}_{0.5} \mathrm{Sr}_{0.5} \mathrm{Fe}_{12} \mathrm{O}_{19}$ is shown in Figure. 1 and X-ray diffraction data are enumerated in tables 1 .

The lattice parameters, X-ray density, bulk density, porosity and grain size were calculated for each sample. The magnetic properties of polycrystalline sample have been measured by using a vibrating sample magnetometer in the applied field upto $10 \mathrm{KG}$ at room temperature Figure. 2. In order to avoid rotation of the powder grain, pressed samples were used. The transition temperature (Tc) has been measure by using a Gouy's balance.

\section{Result and discussions:}

The recorded X-ray diffraction pattern of all the samples shows that all these lines belongs to hexagonal structure. The reflection from the planes (006), (113), (200), (0012), (220), (304) appears for all the samples. The appearance of these planes proved that the samples are M-type ferrite depicted in table 2.

The interplaner distance $\mathrm{d}(\hat{\AA})$ was calculated using Bragg's law and the value of lattice constant ' $a$ ' $(\AA \overline{)})$ were determined with an accuracy of $0.002 \AA$. The observed and calculated values of the interplaner distances for the sample $\mathrm{Ca}_{0.5} \mathrm{Sr}_{0.5} \mathrm{Fe}_{12} \mathrm{O}_{19}$ are depicted in table-1. Thus obeying the Regard's law which may be attributed to the replacement of smaller $\mathrm{Fe}^{3+}$ ions $(0.64 \AA)$ by larger ionic radii of the combinations of ( CoAl /CoTi ) ions in $\mathrm{Ca}_{0.5} \mathrm{Sr}_{0.5} \mathrm{Me}_{\mathrm{x}} \mathrm{Fe}_{12-2 \mathrm{x}} \mathrm{O}_{19}$ system.

The $\mathrm{X}$-ray density is given in the Table-2, the variation of X-ray density with the concentration of CoAl, CoTi with Sr, which may be due to the ionic difference between $\mathrm{Al}^{+3}(0.50 \AA)$ and $\mathrm{Ti}^{+3}$ $(0.95 \AA)$ as reported in the literature [7-8] or due to specific gravity of cations.

The porosity of all samples was found in the range of $39-42 \%$. The bulk density is determined and value as a function of concentration is given in table-3, it is observed that the bulk density increases with concentration (CoAl / CoTi). At sintering temperature of $1040{ }^{\circ} \mathrm{C}$, the number of pores is reduced, as a result of which individual grains come closer to each other and the effective area of grain to grain contact increases as also described [8].

The particle morphology of the samples was observed using a SEM the photographs were shown in fig- 3 . The sample comprises hexagonal particles with their average grain size between $0.29 \mu \mathrm{m}$ to $0.87 \mu \mathrm{m}$, indicating improved homogeneity and grain size reduction of the starting powders.

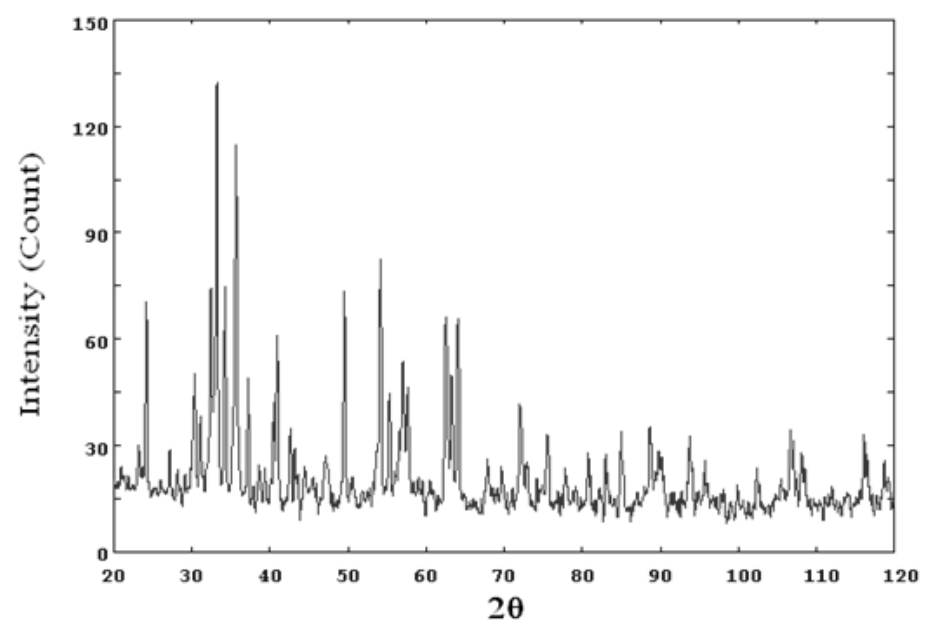

Figure. 1. XRD of compound $\mathrm{Ca}_{0.5} \mathrm{Sr}_{0.5} \mathrm{Fe}_{12} \mathrm{O}_{19}$ 

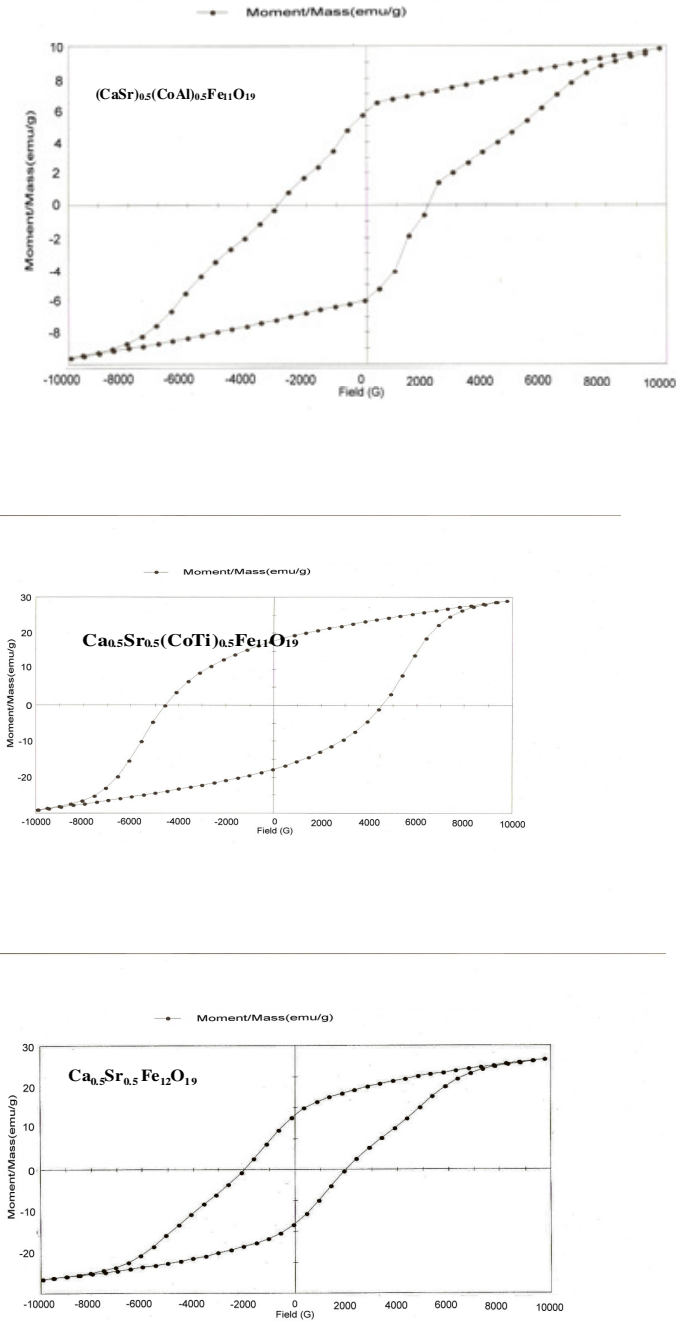

Figure. $2 \mathrm{BH}$ curve of compounds

(a) $\mathrm{Ca}_{0.5} \mathrm{Sr}_{0.5}(\mathrm{CoAl})_{0.5} \mathrm{Fe}_{11} \mathrm{O}_{19}$

(b) $\mathrm{Ca}_{0.5} \mathrm{Sr}_{0.5}$ (CoTi) $0.5 \mathrm{Fe}_{11} \mathrm{O}_{19}$ (c) $\mathrm{Ca}_{0.5} \mathrm{Sr}_{0.5} \mathrm{Fe}_{12} \mathrm{O}_{19}$

In table 4. we have summarized the crystallographic characteristics of five different sublattice together with the spin alignments corresponding to the collinear magnetic structure proposed [9]. The value of saturation magnetization per formula unit in Bohr magnetron $\left(\eta_{\mathrm{B}}\right)$ at $300 \mathrm{~K}$ for all the samples obtained from field dependence of magnetization is given in table-5. The variation of saturation magnetization Ms and $\eta_{B}$ per formula unit with concentration of CoTi, CoAl are shown in table4. It is seen that the value of $\left(\eta_{B}\right)$ gradually increases with retentivity and saturation magnetization.

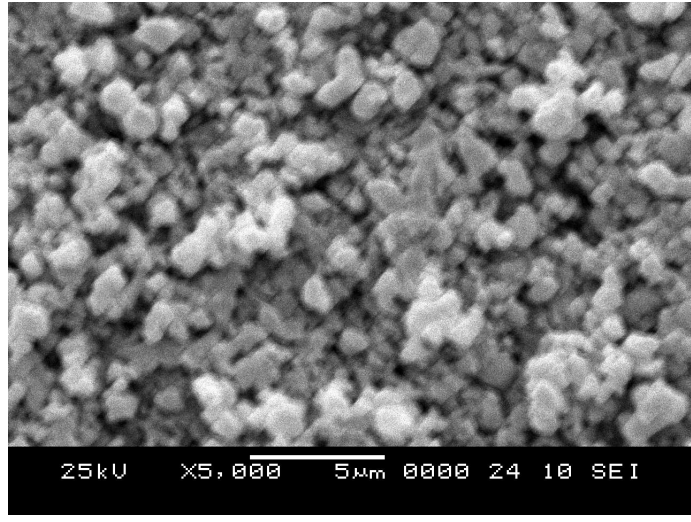

(a) $\mathrm{Ca}_{0.5} \mathrm{Sr}_{0.5} \mathrm{Fe}_{12} \mathrm{O}_{19}$

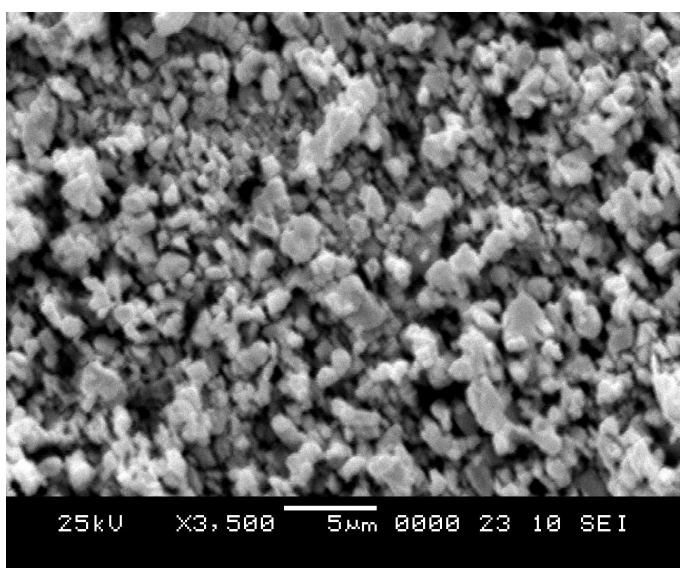

(b)Cao.5Sro.5(CoTi)0.5Fe $11 \mathrm{O}_{19}$

Figure. 3 SEM micrographs of the compounds
The results for compounds $\mathrm{Ca}_{0.5} \mathrm{Sr}_{0.5} \mathrm{Fe}_{12} \mathrm{O}_{19}$ here after abbreviated as [sample (c)] are compared with Ca0.5Sro.5(CoAl) $0.5 \mathrm{Fe}_{11} \mathrm{O}_{19} \quad$ [sample (a)] and Ca0.5 $\mathrm{Sr}_{0.5}(\mathrm{CoTi})_{0.5} \mathrm{Fe}_{11} \mathrm{O}_{19}$ [sample (b)] then it is found that, saturation magnetization, magnetic moment, and retentivity values are larger for sample (c) than sample (a) and sample (b) compound. But coercivity declines for sample (b) than sample (a). This is due to the decrease of Fe content; the contribution towards saturation magnetization due to $\mathrm{Fe}-\mathrm{O}-\mathrm{Fe}$ exchange interaction gets reduced. The behaviour is in good agreement to that observe by [10-12] etc., when $\mathrm{Fe}$ is substituted by $\mathrm{Al}, \mathrm{Ga}$ and $\mathrm{Cr}$ in $\mathrm{M}$ - 
ferrites, affect the lattice dimensions, site distribution, Curie temperature and saturation magnetization. It is observed that saturation magnetization decreases when $\mathrm{Fe}$ is substituted by $\mathrm{Co}^{+2}$ and $\mathrm{Ti}^{+4}$ with increasing concentration. In compound $\mathrm{Ca}_{0.5} \mathrm{Sr}_{0.5}(\mathrm{CoTi})_{0.5} \mathrm{Fe}_{11} \mathrm{O}_{19}$, the magnetic moment from the octahedraly surrounded ferric ions in the spinel blocks and those in the trigonal bipyramidal sites are opposed by a minority of ferric ions in tetrahedral sites of the spinel block along with octahedral sites. Which in case of compound $\mathrm{Ca}_{0.5} \mathrm{Sr}_{0.5}(\mathrm{CoTi})_{0.5} \mathrm{Fe}_{11} \mathrm{O}_{19}$ larger value of saturation magnetization is observed which is obvious as substitution of ferrimagnetic ions such as CoTi in spinel blocks of the M-structure occupying the octahedral sites (12k), the interaction energy increase so high, which in turn increases the saturation magnetization [13].

The $\mathrm{BH}$ curve measurements were carried out at room temperature. The observed results are explained on the basis of site distribution. The saturation magnetization, coerecivity, magnetic moment and retentivity decreased with CoAl and CoTi substitution. It is evident from the fact that $\mathrm{Al}$ and $\mathrm{Ti}$ ions are non magnetic in nature. In this compound the magnetic moment from octahedraly surrounded ferric ions in the spinal blocks and those in the trigonal bipyramidal sites are opposed by a minority of ferric ions in tetrahedral sites of the spinel block along with octahedral sites.

The large value of $\mathrm{Ms}, \mathrm{Hc}, \eta_{в}$ is attributed to the fact that the interaction energy is so high, which in turn increases the saturation magnetization [14] have shown that the interaction $2 \mathrm{a}-12 \mathrm{k}$ is of immense importance and determines the magnetic behaviour of the compounds. The $\mathrm{Fe}^{+3}$ ions have high magnitude of super exchange and interactions, particularly when all the 24 sites $\left(2 \mathrm{a}, 2 \mathrm{~b}, 4 \mathrm{f}_{1}, 4 \mathrm{f}_{2}\right.$ and $\left.12 \mathrm{k}\right)$ are filled in by magnets and ferromagnetic ions alone $\mathrm{Fe}(12 \mathrm{k})$ sublattice making the link along octahedral R-S structural blocks is subjected to very strong competitive exchange interaction table 5 .

A plot of inverse molar magnetic susceptibility versus temperature $(\mathrm{T})$ is linear for the samples containing CoTi and CoAl ions, resembles ferromagnetic behaviour. The temperature dependence of magnetic susceptibility measurement showed that the Curie temperature of sample (a), (b) and (c) are 599, 516 and $547 \mathrm{~K}$ respectively. The variation in magnetic ordering temperature has variation amongst the compounds, as the magnetic moment of $\mathrm{Co}^{+3}$ and $\mathrm{Fe}^{+3}$ ions are different a ferromagnetic is formed. The canting is not worked out in this case the canting of A-B interaction play a complex role such that almost a feeble magnetic anti-ferrimagnetic exchange is involved and hence a lesser degree of curvature is observed in the present case. The high value of Tc $(599 \mathrm{~K})$ demonstrates that some intersubstitute exchange interaction between two close sites, are decisive for strong magnetic characters. [15-17] while the low value of Tc $(516 \mathrm{~K})$ sample $(\mathrm{B})$ means that the cations of the additive substitute for the $\mathrm{Fe}^{+3}$ of the $2 \mathrm{~b}$ or the $12 \mathrm{k}$ sites will weaken the total distance or angle due to the superexchange interaction $\mathrm{Fe}-\mathrm{O}-\mathrm{Fe}$ [18].

The interaction between close site such as $2 \mathrm{a}-2 \mathrm{k}, 2 \mathrm{a}-4 \mathrm{f}_{1}$, and $4 \mathrm{f}_{1}-12 \mathrm{k}$ are decisive for strong magnetic character. Whenever magnets ions are present in these sites, strengthening of super exchange interaction produces an increase in the magnetic characteristics such as Curie temperature, magnetization. In case of $\mathrm{M}$ structure, the orientations of the magnetic moments of the ferric ions in the crystals are generally aligned along the c-axis in antiparallel with each other.

The neutron diffraction and NMR studies in BaM- ferrites [19] shows that the $\mathrm{Ti}^{+4}$ ions are mainly distributed with $4 \mathrm{f}_{2}$ and $12 \mathrm{k}$ sites $\mathrm{Co}^{+2}$ ions occupy mainly $4 \mathrm{f}_{1}$ and $12 \mathrm{k}$ sites [20], because of $4 f_{1}$ and $4 f_{2}$ with down spin have larger value of magnetic moment can be obtained according the cationic distribution deduced from the neutron $\&$ NMR studies using the Gorter collinear spin model.

A mean field analysis of the exchange interaction in M-type hexaferrite has been carried out by [20-22]. The result shows that the Fe (12k) sublattice making link among R-S structural blocks is subject to very strong competitive exchange interaction. So when $\mathrm{Fe}^{+3}$ ions in the $12 \mathrm{k}$ sublattice are subjected to non magnets viz. $\mathrm{Ti}^{+4}$ or $\mathrm{Al}^{+3}$ ions weaking of superexchange interaction between magnetic ions results in a fairly inclined ferrimagnetism [2324].

Table - $1 \quad \mathbf{X}$ - Ray diffraction Result of Ca0.5 $\mathrm{Sr}_{0.5} \mathrm{Fe}_{12} \mathrm{O}_{19}$ with lattice parameter $\mathrm{a}=$ $5.8130 \pm 0.0008 \AA, c=22.0398 \pm 0.0009 \AA$

\begin{tabular}{|c|c|c|ccc|}
\hline $\begin{array}{c}\mathbf{d}_{\text {obs }} \\
(\hat{\AA})\end{array}$ & $\begin{array}{c}\mathbf{d}_{\text {cal }} \\
(\hat{A})\end{array}$ & $\begin{array}{c}\mathbf{l}_{\text {obs }} \\
(\%)\end{array}$ & $\mathbf{h}$ & $\mathbf{k}$ & $\mathbf{~}$ \\
\hline & & & & & \\
3.6733 & 3.6732 & 32.7 & 0 & 0 & 6 \\
2.6970 & 2.7026 & 100.0 & 1 & 1 & 3 \\
2.5171 & 2.5171 & 67.2 & 2 & 0 & 0 \\
2.4153 & 2.4159 & 31.0 & 1 & 0 & 8 \\
2.2055 & 2.2049 & 27.7 & 0 & 0 & 10 \\
1.8418 & 1.8418 & 35.3 & 2 & 1 & 3 \\
\hline
\end{tabular}




\begin{tabular}{|c|c|c|c|c|c|}
\hline 1.8366 & 1.8366 & 21.0 & 0 & 0 & 12 \\
\hline & 1.6954 & 55.4 & 0 & 0 & 13 \\
\hline h k l & 1.6476 & 5.4 & 1 & 1 & 11 \\
\hline & 1.6330 & 15.9 & 3 & 0 & 3 \\
\hline & 1.6022 & 13.6 & 3 & 0 & 4 \\
\hline & 1.4876 & 24.6 & 2 & 0 & 12 \\
\hline 006 & 1.4542 & 38.9 & 2 & 2 & 0 \\
\hline 113 & 1.3838 & 6.9 & 1 & 1 & 14 \\
\hline 200 & 1.3128 & 10.9 & 1 & 1 & 15 \\
\hline $\begin{array}{ll}0 & 0\end{array}$ & 1.2984 & 7.7 & 0 & 0 & 17 \\
\hline & 1.2594 & 3.3 & 1 & 0 & 17 \\
\hline 12 & 1.1916 & 3.8 & 3 & 0 & 13 \\
\hline 304 & 1.1435 & 6.2 & 3 & 1 & 11 \\
\hline 220 & 1.1049 & 4.1 & 0 & 0 & 20 \\
\hline 1.6954 & 1.0575 & 5.8 & 2 & 0 & 19 \\
\hline 1.6459 & 1.0435 & 3.5 & 3 & 1 & 14 \\
\hline 1.6301 & 0.9626 & 5.8 & 2 & 0 & 21 \\
\hline 1.6010 & 0.9536 & 7.3 & 2 & 1 & 20 \\
\hline 1.4871 & & & & & \\
\hline 1.4547 & & & & & \\
\hline 1.3833 & & & & & \\
\hline 1.3130 & & & & & \\
\hline 1.2999 & & & & & \\
\hline 1.2594 & & & & & \\
\hline 1.1914 & & & & & \\
\hline 1.1428 & & & & & \\
\hline
\end{tabular}

\begin{tabular}{|l|l|l|l|}
\hline 1.1040 & & & \\
1.0574 & & & \\
1.0410 & & & \\
0.9624 & & & \\
0.9535 & & & \\
\hline
\end{tabular}

Table. 2. Comparative $d-$ values of various samples of the series $\mathrm{Ca}_{0 .} \mathrm{Sr}_{0.5} \mathrm{Me}_{\mathrm{x}} \mathrm{Fe}_{12-2 \mathrm{x}} \mathrm{O}_{19}$

Table-3. X-ray diffraction analysis data

\begin{tabular}{|c|c|c|c|c|c|c|}
\hline Compound & $\mathrm{a}(\hat{\AA})$ & c $(\AA \bar{A})$ & $\begin{array}{l}\text { X-ray density } \\
\left(\mathrm{gm} / \mathrm{cm}^{3}\right)\end{array}$ & $\begin{array}{l}\text { Bulk density } \\
\left(\mathrm{gm} / \mathrm{cm}^{3}\right)\end{array}$ & \begin{tabular}{|l}
$\begin{array}{l}\text { Porosity } \\
(\%)\end{array}$ \\
\end{tabular} & \begin{tabular}{|l}
$\begin{array}{l}\text { Particle size } \\
(\bar{\AA})\end{array}$ \\
\end{tabular} \\
\hline $\begin{array}{l}\mathrm{Ca}_{0.5} \mathrm{Sr}_{0.5}(\mathrm{CoAl})_{0.5} \\
\mathrm{Fe}_{11} \mathrm{O}_{19}\end{array}$ & 5.8234 & 22.0986 & 5.24548 & 3.09244 & 41.045 & 36 \\
\hline $\begin{array}{l}\mathrm{Ca}_{0.5} \mathrm{Sr}_{0.5}(\mathrm{CoT})_{0.5} \\
\mathrm{Fe}_{11} \mathrm{O}_{19}\end{array}$ & 5.8257 & 22.1298 & 5.28735 & 3.18611 & 39.746 & 24 \\
\hline $\begin{array}{l}\mathrm{Ca}_{0.5} \mathrm{Sr}_{0.5} \\
\mathrm{Fe}_{12} \mathrm{O}_{19} \\
\end{array}$ & 5.8130 & 22.0398 & 5.34468 & 3.22206 & 39.714 & 24 \\
\hline
\end{tabular}

Table 4 Five iron lattice sites, their spin direction, type, point symmetry, number of Fe ions per formula, and block situation in M-type ferrite.

\begin{tabular}{|l|l|l|l|l|l|}
\hline Sublattice & Type & $\begin{array}{l}\text { Point } \\
\text { symm } \\
\text { etry }\end{array}$ & Ions & $\begin{array}{l}\text { Spin } \\
\left(5 \mu_{\mathrm{B}}\right)\end{array}$ & Block \\
\hline $12 \mathrm{k}$ & Octahedral & $\uparrow^{\mathrm{m}}$ & 6 & Up & $\mathrm{S}-\mathrm{R}$ \\
\hline $4 \mathrm{f}_{1}$ & Tetrahedral & $\S^{\mathrm{m}}$ & 2 & Down & $\mathrm{S}$ \\
\hline $4 \mathrm{f}_{2}$ & Octahedral & $\downarrow^{\mathrm{m}}$ & 2 & Down & $\mathrm{R}$ \\
\hline $2 \mathrm{a}$ & Octahedral & $\uparrow^{\overline{3} \mathrm{~m}}$ & 1 & $\mathrm{Up}$ & $\mathrm{S}$ \\
\hline $2 \mathrm{~b}$ & Five Fold & $\uparrow^{\overline{6} \mathrm{~m} 2}$ & 1 & $\mathrm{Up}$ & $\mathrm{R}$ \\
\hline
\end{tabular}

Table-5. Various magnetic parameters

\begin{tabular}{|l|l|l|l|l|l|}
\hline Compound & $\begin{array}{l}\text { Ms } \\
\text { Magnetiz } \\
\text { ation }\end{array}$ & $\begin{array}{l}\text { Retentivity } \\
\text { emu/g }\end{array}$ & $\begin{array}{l}\text { Hci } \\
\text { Coercivit } \\
\mathrm{y}\end{array}$ & $\eta_{\mathrm{B}}$ & $\begin{array}{l}\text { Tc } \\
(\mathrm{K})\end{array}$ \\
\hline
\end{tabular}




\begin{tabular}{|l|l|l|l|l|l|}
\hline & $\mathrm{emu} / \mathrm{g}$ & & $(\mathrm{G})$ & & \\
\hline $\mathrm{Ca} 0.5 \mathrm{Sr}_{0.5}(\mathrm{CoAl})_{0.5} \mathrm{Fe}_{11} \mathrm{O}_{19}$ & 9.7155 & 5.8900 & 2498.2 & 1.7832 & 599 \\
\hline $\mathrm{Ca} .5 \mathrm{Sr}_{0.5}(\mathrm{CoTi})_{0.5} \mathrm{Fe}_{11} \mathrm{O}_{19}$ & 17.740 & 8.7701 & 1986.7 & 3.2893 & 516 \\
\hline $\mathrm{Ca} .5 \mathrm{Sr}_{0.5} \mathrm{Fe}_{12} \mathrm{O}_{19}$ & 29.052 & 17.773 & 4562.3 & 5.3994 & 547 \\
\hline
\end{tabular}

\section{Reference:}

1) J I Kraschwitz, Mary Howe-grami, Encyclopedia of chemical Technology, vol. 10 IVth Ed. (1993) 381

2) H Kojima (1982) in Ferromagnetic material

3) $M \quad H$ Abdullah and $\mathbf{S} H$ Ahmel Sains malaysians (1993) 22 P I

4) D E Speliolis IEEE Trans. magn. MAG(1987) 23-25

5) X. Z Zhou, A H Morrish, Z W Li and Y K Hang, IEEE Trans. Magn. Mag-27, (1991) 4654

6) Seung Iel Park, Seung Wha Lee and Chul Sung Kim J. Korean Phys. Soc. Vol 31(1997) 193- 196

7) T Abbas, Y Kham, M Ahmad and S Anwar, solid state commun 82 (1992) 701

8) M K Moinuddin and S R Murthy J. Alloys compound. 194 (1993) 105

9) $\mathbf{E} \mathbf{W}$ Gorter, IEEE Trans. magn. 104B (1957) 255

10) E F Bertant, A Deschamps, R Pauthenet and S Pickart, J. De. Phys. 20 (1959) 404

11) $\mathbf{Y}$ Goto and $\mathbf{K}$ Takahashi, Jap. J Appl. Phys. 12 (1973) 948

12) G Albanese, M Carbucicchio and A Deriu, Phys. Stat. Sol. A23 (1974) 351

13) $\mathbf{X}$ Obradors, $\mathbf{A}$ Isalque, Collomb, $\mathbf{A}$ Labarta, M Pernet, $\mathbf{J}$ A Pereda, $\mathbf{J}$ Tejada and $\mathbf{J}$ C Joubert, J. Phys. C 19 (1986) 6605
14) H Stepankova, J Kohout and $\mathbf{Z}$ Sismsa Proc. 1CM (Amsterdons; North-Holland) vol 3 (1991) 705

15) L G Van Uitert, J. Appl. Phys. 28 (1957) 317

16) G Turilli, F Liali, S Rinaldi, J. Magn. Mater. 59 (1986) 127

17) K G Rewatkar, N M Patil, S Jaykumar, D S Bhowmick, M N Giriya and C L Khobragade, JMMM 316 (2007) 19-22

18) Y J Oh, I B Shim, H J Jung, J Y Park, S I Park, Y R Um, Y J Lee, $\mathbf{S} \mathbf{H}$ Lee and $\mathbf{C} \mathbf{S}$ Kim, J. Appl. Phys. 76 (1994) 6877

19) B X Gu., H Y Zhang, H R Zhai, B G Shen, M Lu , S Y Zhang and Y Maoi, J. Phys Status Solidi (A), 133 (1992) K 83

20) A Isalgue, A Laberta, J Tejada, $\mathbf{X}$ Obradors, Appl. Phys. A 39 (1986) 221

21) K G Rewatkar, N M Patil and S R Gawali Bull. Mater. Sci Vol.28. Nov. Oct (2005) 585-587.

22) C M Fang, F Kools, R Metselaar, G de With and $\mathbf{R} \mathbf{A}$ de Groot J. Phys. Condens matter 15 (2003) 6229-6237

23) A M Sankalp, s s Suryavanshi, s V kakatkar, G C Tengshe, $R$ S Patil, N D Chaudhari and S R Sawant JMMM Vol. 186 (1998) 349-356

24) G Mendoza-Suarez, L P Rivas-Vaquez, J C Corral-Huacuz, A F Fuentes and EscalanteGarcia, condensed matter Vol. 339 (2003) 110118 